\title{
Characterization of different strains of common carp (Cyprinus carpio L.) (Cyprinidae, Cypriniformes) in Bangladesh using microsatellite DNA markers
}

\author{
Md. Rashedul Kabir Mondol ${ }^{1}$, Md. Shahidul Islam² and Md. Samsul Alam ${ }^{1}$ \\ ${ }^{1}$ Department of Fisheries Biology and Genetics, Bangladesh Agricultural University, Mymensingh, \\ Bangladesh. \\ ${ }^{2}$ Department of Biotechnology, Bangladesh Agricultural University, Mymensingh, Bangladesh.
}

\begin{abstract}
Characterization of different strains of common carp (Cyprinus carpio L.) using molecular markers is essential for the management of this fish in respect to the evaluation of the potential genetic effects induced by hatchery operations and the genetic improvement of carp varieties. Five microsatellite loci (MFW1, MFW2, MFW11, MFW15 and MFW20) were analyzed for the molecular characterization of four common carp strains, i.e. scaled carp, mirror carp, red carp and koi carp. We observed differences in heterozygosities and the average numbers of alleles but not in polymorphic loci $\left(P_{95}\right)$ among the strains. Koi carp displayed the highest level of variability in terms of heterozygosity. The $N_{\mathrm{m}}$ values and the $F_{\mathrm{ST}}$ values indicated a low level of gene flow and high level of differentiation among the strains. The highest genetic distance was observed between the scaled carp and the koi carp whilst the lowest genetic distance was found between the red- and koi carp. The unweighted pair group method with averages (UPGMA) dendrogram resulted in two clusters, one containing only the scaled carp and the other the remaining three varieties. Microsatellite markers have been found to be effective tools for characterization of different strains of common carp.
\end{abstract}

Key words: characterization, Cyprinus carpio, microsatellite marker.

Received: August 4, 2005; Accepted: May 8, 2006.

\section{Introduction}

The common carp (Cyprinus carpio L.) belongs to the Cyprinidae, the largest freshwater teleost family (Nelson, 1994), and is probably the oldest and most extensively cultured fish species in the world. The total annual world production of common carp in 2003 has been estimated to be 3 239712 tons (FAO, 2005) and this fish has been acclimatized to a wide range of habitats and environmental conditions and therefore enjoys a world-wide distribution. Different varieties of common carp (e.g. races, landraces, strains, breeds and stocks) have been developed through a combination of forces including geographical isolation, adaptation, accumulation of mutations and natural as well as human selection pressure (Hulata, 1995). The colourful koi, or fancy, carp was developed in Japan for ornamental purposes, probably from colour mutant types arising in the wild carp (Magoi) of Central Asia (McDowall, 1989). Other commercial stocks (e.g. gold, red and white, tricolour etc.) have been established by selective breeding and cross breeding of colour mutants (Purdom, 1993, Liu et al., 2002).

Send correspondence to Md. Samsul Alam. Department of Fisheries Biology and Genetics, Bangladesh Agricultural University, Mymensingh 2202, Bangladesh. E-mail: samsul_bau@yahoo.com.
As many as 15 exotic fishes (Ali, 1998) have been introduced into Bangladesh, although the common carp is the most important fish that is being extensively cultured throughout the country. Scaled common carp was first introduced into Bangladesh by the Bangladesh Department of Fisheries (DoF) in 1960 from China and then in 1995 from Vietnam. The mirror carp was first introduced into Bangladesh in 1979 from Nepal and then from Hungary in 1982 and 1996 (Rahman, 1985; Hussain, 1997). Koi carp has recently been introduced from Japan and successfully bred in hatcheries in the Jessore district of Bangladesh.

In Bangladesh, common carp is repeatedly bred in the hatchery with a limited number of effective parents $\left(N_{\mathrm{e}}\right)$ to keep the production costs to a minimum. As a result, genetic erosion may have occurred through inbreeding, genetic drift and the bottleneck effects. Rare alleles may be lost through genetic drift during management of hatchery stocks. According to Basavaraju et al. (2002) precocious maturation, unwanted reproduction and loss of genetic variability have been identified as potential constraints of common carp aquaculture and culture-based fisheries. Moreover, hatchery owners, especially in the Jessore region, sometimes conduct cross-breeding among different strains of common carp to produce attractive colored fish to 
meet public demand (personal communication). This may lead to the introgression of genes causing loss of the genetic identity of the respective strains. All of these negative management practices have been identified as potential constraints in common carp aquaculture and culture-based fisheries in Bangladesh and it is imperative to assess any possible genetic erosion that might have been induced by Bangladeshi hatchery management practices.

DNA microsatellites are the most useful markers that are widely and efficiently used in the evaluation of the genetic status of different organisms. These markers are highly polymorphic tandem arrays of short nucleotide motifs dispersed throughout the nuclear genome of eukaryotes (Hamada et al., 1982; Crooijmans et al., 1997) and have recently been used successfully for monitoring genetic diversity in different common carp strains (Tanck et al., 2000; David et al., 2001; Lehoczky et al., 2002; Bartfai et al., 2003; Kohlmann et al., 2003).

The study described in this paper examined the levels of genetic polymorphism in different strains of common carp in Bangladesh using microsatellite DNA markers developed by Crooijmans et al. (1997). This study will also provide a genetic background for the management of different strains of common carp in the hatcheries and contribute to the identification and characterization of common carp in Bangladesh.

\section{Materials and Methods}

\section{Sample collection}

Fingerlings of four strains were collected from Anil Fishery, Mymensingh district and Sonali Matsha Hatchery, Jessore district, Bangladesh during August to September of 2004. The Fingerlings were reared for four months in different ponds at the field laboratory complex of the Faculty of Fisheries, Bangladesh Agricultural University, Mymensingh. In order to perform microsatellite analysis, samples of fin tissues were cut with scissors from 25 randomly-selected specimens of each strain and immediately preserved in $95 \%(\mathrm{v} / \mathrm{v})$ ethanol and stored at $-20^{\circ} \mathrm{C}$.

\section{Genomic DNA extraction}

For each sample, approximately $30 \mathrm{mg}$ of fin tissues was cut into small pieces and genomic DNA was extracted by proteinase-K digestion, phenol:chloroform:isoamyl alcohol $(25: 24: 1 \mathrm{v} / \mathrm{v} / \mathrm{v})$ extraction and ethanol precipitation as described by Alam et al. (1996). In brief, tissue samples was homogenized and digested with proteinase- $\mathrm{K}$ in extraction buffer [100 mM Tris-HCl, $10 \mathrm{mM}$ ethylenediaminetetraacetic acid (EDTA), $250 \mathrm{mM} \mathrm{NaCl}$ and $1 \%(\mathrm{w} / \mathrm{v})$ sodium dodecyl sulfate (SDS); $\mathrm{pH} 8.0$ ] at $37^{\circ} \mathrm{C}$ overnight. Tissue lysate was purified twice with phenol:chloroform: isoamyl alcohol $(25: 24: 1 \mathrm{v} / \mathrm{v} / \mathrm{v})$ and once with chloroform:isoamyl alcohol $(24: 1 \mathrm{v} / \mathrm{v})$. The DNA was precipitated first using 0.6 volumes of isopropanol, pelleted by centrifugation and suspended in TE $(10 \mathrm{mM}$ Tris- $\mathrm{HCl}$ and 1 mM EDTA; pH 8.0) buffer. DNA was re-precipitated by adding twice the volume of absolute ethanol and pelleted by centrifugation. The pellets were then washed with $70 \%$ $(\mathrm{v} / \mathrm{v})$ aqueous ethanol, air dried and re-suspended in an appropriate volume of TE buffer. The quality of the extracted DNA sample was checked by electrophoresis in $1 \%(\mathrm{w} / \mathrm{v})$ agarose gel and the quantity of the DNA in each sample was determined by UV-spectrophotometry.

\section{Polymerase chain reaction (PCR) amplification of microsatellite DNA marker}

A total of five poly (CA) type primer pairs $(M F W 1$, MFW2, MFW11, MFW15 and MFW20) developed by Crooijmans et al. (1997) were used in the study. The amplification conditions recommended by Crooijmans et al. (1997) were followed with some modification especially in annealing temperature and template DNA concentration. The annealing temperatures of the five primer pairs were $55^{\circ} \mathrm{C}$ for $M F W 20,56{ }^{\circ} \mathrm{C}$ for $M F W 1, M F W 11$ and $M F W 15$, and $57^{\circ} \mathrm{C}$ for $M F W 2$. The PCR was performed in a $10 \mu \mathrm{L}$ reaction volume containing 25-50 $\mathrm{ng}$ of template DNA, $2.5 \mu \mathrm{M}$ of forward and reverse primer, $0.25 \mathrm{mM}$ of each dNTP, 1 unit of Taq DNA polymerase and $1 \mu \mathrm{L}$ of $10 \mathrm{x}$ reaction buffer containing $15 \mathrm{mM} \mathrm{MgCl}$. The PCR cycles were: pre-amplification denaturation at $94{ }^{\circ} \mathrm{C}$ for $3 \mathrm{~min}$, then $30 \mathrm{~s}$ at $94^{\circ} \mathrm{C}, 30 \mathrm{~s}$ at the respective annealing temperature and $1 \mathrm{~min}$ at $72{ }^{\circ} \mathrm{C}$ for 35 cycles followed by a final elongation step for $5 \mathrm{~min}$ at $72{ }^{\circ} \mathrm{C}$.

\section{Gel electrophoresis and staining}

The PCR products were separated by electrophoreses on $6 \%(\mathrm{w} / \mathrm{v})$ denatured polyacrylamide gel containing 19:1 acrylamide:bis-acrylamide and $7 \mathrm{M}$ urea using a Sequi-Gen sequencing gel electrophoresis system (BIO-RAD Laboratories, Hercules, CA). The gel was pre-run for $30 \mathrm{~min}$ at $120 \mathrm{~W}$ followed by final run at $60 \mathrm{~W}$ and $50^{\circ} \mathrm{C}$ for $2-3 \mathrm{~h} \mathrm{ac}-$ cording to the size of the PCR fragment. After electrophoresis the gel was stained with silver nitrate essentially following the Promega (Madison, WI) silver staining protocol.

\section{Microsatellite data analysis}

Following polyacrylamide gel electrophoresis and silver nitrate staining, one or two clear bands were observed at each locus for each specimen. The bands representing alleles at the microsatellite loci were manually scored based on their sizes and designated as A, B, C, D, E, F, G, I, H, J and $\mathrm{K}$ from the bottom to the top of the gel. The DNA FRAG program version 3.03 (Nash, 1991) was used to estimate the size (allelic length) of the fragments. To calculate the microsatellite length, a standard $100 \mathrm{bp}$ DNA ladder marker was run on each side of the gel. The DNAfrag program was used to calculate a standard curve of the standard DNA bands using their mobilities (in $\mathrm{mm}$ ) and the 'least 
squares fit of DNA fragment length to gel mobility' algorithm of Schaffer and Sederoff (1981). Allelic variations, fit to Hardy-Weinberg proportions and gene flow $\left(N_{\mathrm{m}}\right)$ were estimated using the POPGENE program version 1.31 (Yeh et al., 1999) with 1000 simulated samples. The G-stat program (Siegismund, 1995) was used for estimating allelic frequencies and homogeneity test between the strains. The FSTAT program version 2.9.3 (Goudet, 2001) was used to calculate F-statistics $\left(F_{\mathrm{ST}}\right)$ between strains. The GDA program (Lewis and Zaykin, 2001) was used for estimating genetic distance. The unweighted pair-group method with averages (UPGMA) dendrogram was drawn using TREEVIEW program (Page, 1996).

\section{Results}

\section{Intra-population genetic variation}

All the microsatellite loci subjected to PCR amplification were found to be polymorphic (p) (Table 1). The $M F W 15$ locus had the highest number of alleles (11) while the MFW20 locus had the least (3). The average number of alleles across all loci was the highest (7.40) in the red carp

Table 1 - Allelic variations ( $N$ = number of alleles, $H_{\mathrm{o}}=$ observed heterozygosity, $H_{\mathrm{e}}=$ expected heterozygosity) and deviation from Hardy-Weinberg $(\mathrm{H}-\mathrm{W})$ expectations ( $\chi^{2}$ values) at five microsatellite loci in twenty five fish from each of the four common carp strains studied.

\begin{tabular}{|c|c|c|c|c|}
\hline \multirow[b]{2}{*}{ Microsatellite loci } & \multicolumn{4}{|c|}{ Common carp strain $^{1}$} \\
\hline & Scaled carp & Mirror carp & Red carp & Koi carp \\
\hline \multicolumn{5}{|l|}{$M F W 1$} \\
\hline $\mathrm{N}$ & 9 & 8 & 8 & 8 \\
\hline$H_{\mathrm{o}}$ & 0.40 & 0.85 & 0.85 & 0.90 \\
\hline$H_{\mathrm{e}}$ & 0.85 & 0.82 & 0.85 & 0.83 \\
\hline $1-H_{\mathrm{o}} / H_{\mathrm{e}}$ & 0.53 & -0.04 & 0.00 & -0.08 \\
\hline $\mathrm{H}-\mathrm{W}$ test & $73.12(36)^{* * *}$ & $91.71(28)^{* * * *}$ & $30.73(28)^{\mathrm{NS}}$ & $30.80(28)^{\mathrm{NS}}$ \\
\hline \multicolumn{5}{|l|}{$M F W 2$} \\
\hline$N$ & 5 & 5 & 7 & 7 \\
\hline$H_{\mathrm{o}}$ & 0.40 & 0.70 & 0.65 & 0.80 \\
\hline $\mathrm{He}$ & 0.74 & 0.77 & 0.84 & 0.71 \\
\hline $1-H_{\mathrm{o}} / H_{\mathrm{e}}$ & 0.46 & 0.09 & 0.23 & -0.12 \\
\hline H-W test & $20.31(10)^{*}$ & $7.58(10)^{\mathrm{NS}}$ & $34.15(21)^{*}$ & $74.21(21)^{* * * *}$ \\
\hline \multicolumn{5}{|l|}{$M F W 11$} \\
\hline $\mathrm{N}$ & 6 & 5 & 6 & 5 \\
\hline$H_{\mathrm{o}}$ & 0.10 & 0.40 & 0.55 & 0.25 \\
\hline$H_{\mathrm{e}}$ & 0.83 & 0.62 & 0.82 & 0.71 \\
\hline $1-H_{\mathrm{o}} / H_{\mathrm{e}}$ & 0.88 & 0.35 & 0.33 & 0.65 \\
\hline $\mathrm{H}-\mathrm{W}$ test & $105.15(15)^{* * * *}$ & $20.17(10)^{*}$ & $66.34(15)^{* * * *}$ & $37.59(10)^{* * *}$ \\
\hline \multicolumn{5}{|l|}{$M F W 15$} \\
\hline $\mathrm{N}$ & 10 & 9 & 11 & 10 \\
\hline$H_{\mathrm{o}}$ & 1.00 & 1.00 & 1.00 & 1.00 \\
\hline$H_{\mathrm{e}}$ & 0.87 & 0.88 & 0.90 & 0.90 \\
\hline $1-H_{\mathrm{o}} / H_{\mathrm{e}}$ & -0.15 & -0.13 & -0.11 & -0.11 \\
\hline $\mathrm{H}-\mathrm{W}$ test & $39.01(45)^{\mathrm{NS}}$ & $36.97(36)^{\mathrm{NS}}$ & $56.75(45)^{\mathrm{NS}}$ & $54.25(45)^{\mathrm{NS}}$ \\
\hline \multicolumn{5}{|l|}{$M F W 20$} \\
\hline $\mathrm{N}$ & 4 & 3 & 5 & 5 \\
\hline$H_{\mathrm{o}}$ & 0.65 & 0.50 & 0.50 & 0.85 \\
\hline$H_{\mathrm{e}}$ & 0.68 & 0.67 & 0.69 & 0.79 \\
\hline $1-H_{\mathrm{o}} / H_{\mathrm{e}}$ & 0.05 & 0.26 & 0.28 & -0.08 \\
\hline $\mathrm{H}-\mathrm{W}$ test & $8.09(6)^{\mathrm{NS}}$ & $6.25(3)^{\mathrm{NS}}$ & $17.47(10)^{\mathrm{NS}}$ & $21.48(10)^{*}$ \\
\hline Average $H_{\mathrm{o}}$ over loci & 0.51 & 0.69 & 0.71 & 0.76 \\
\hline Average $H_{\mathrm{e}}$ over loci & 0.79 & 0.75 & 0.82 & 0.79 \\
\hline Average number of alleles & 6.80 & 6.00 & 7.40 & 7.00 \\
\hline Polymorphism $\left(P_{95}\right)$ & 1.00 & 1.00 & 1.00 & 1.00 \\
\hline
\end{tabular}

${ }^{1}$ Values in parentheses indicate degrees of freedom and statistically significant values are indicated as follows: ${ }^{\mathrm{p}} \mathrm{p}<0.05 ; * * \mathrm{p}<0.01 ; * * * \mathrm{p}<0.001$; $* * * * \mathrm{p}=0$. and $\mathrm{NS}=$ not significant. 
followed by the koi carp (7.00), scaled carp (6.80) and mirror carp (6.00).

The observed average heterozygosity $\left(H_{\mathrm{o}}\right)$ in the koi carp was the highest $(0.76)$ which was followed by that of red carp (0.71), mirror carp (0.69) and scaled carp (0.51) in descending order (Table 1). Except for the MFW15 locus, in majority of the cases the $1-H_{\mathrm{o}} / H_{\mathrm{e}}$ values were positive in scaled carp, mirror carp and red carp, indicating that those strains were deficient in heterozygosity at most of the loci (Table 1). On the other hand, the $1-H_{\mathrm{o}} / H_{\mathrm{e}}$ values for koi carp were negative in most cases except at locus MFW11, suggesting that the koi carp stock showed an excess of heterozygosity at most of the loci.

The allelic frequencies of all the loci in all the populations are shown in Table 2. The sizes of the alleles ranged from 124 to 264. No strain-specific private allele was found for any strain at any of the five loci. The total number of lost alleles was the highest in mirror carp (9) followed by scaled carp (5), koi carp (4) and red carp (3).

\section{Deviation from Hardy-Weinberg proportion}

In 10 of a total of 20 tests, significant deviations from Hardy-Weinberg expectations (HWE) were detected (Table 1). The test for fit to Hardy-Weinberg proportions revealed that all the strains were found to be deviated from Hardy-Weinberg expectations at locus MFW11 while all of them were found to be in equilibrium at locus MFW15. Only one strain (koi carp) was found to be in disequilibrium at locus $M F W 20$ and at least two strains were in disequilibrium at loci $M F W 1$ and $M F W 2$. Scaled carp and koi carp deviated in 3 loci while mirror carp and red carp deviated in 2 loci (Table 1).

\section{Inter-population genetic structure and genetic distance}

The population differentiation $\left(F_{\mathrm{ST}}\right)$ value between scaled carp and koi carp was the highest $(0.071)$ while the $F_{\text {ST }}$ value between red carp and koi carp was the lowest $(0.023)$. However, $F_{\mathrm{ST}}$ values were found to be statistically significant in most of the population pairs except red and koi carp. The gene flow $\left(N_{\mathrm{m}}\right)$ value between red carp and koi carp across all the studied loci was the highest (9.67) while the lowest $N_{\mathrm{m}}$ value (4.56) was that between scaled carp and koi carp (Table 3 ).

Pair-wise comparisons of the samples of four strains of C. carpio using homogeneity tests are shown in Table 4. None of the strain pairs was homogenous at locus MFW1 and $M F W 2$. Except for these loci red carp and koi carp were homogenous at all the loci. Scaled carp and mirror carp and scaled carp and red carp were only homogenous at the MFW20 loci. Scaled carp did not form a homogenous group with koi carp at any locus. Mirror carp and red carp and mirror carp and koi carp were homogenous only at locus MFW15 (Table 4).
Table 2 - Frequency of alleles at five microsatellite loci in four common carp strains.

\begin{tabular}{|c|c|c|c|c|}
\hline \multirow[b]{2}{*}{ Allele size (bp) } & \multicolumn{4}{|c|}{ Common carp strain } \\
\hline & Scaled carp & Mirror carp & Red carp & Koi carp \\
\hline \multicolumn{5}{|l|}{$M F W 1$} \\
\hline 200 & 0.03 & 0.15 & 0.17 & 0.32 \\
\hline 192 & 0.05 & 0.35 & 0.00 & 0.08 \\
\hline 180 & 0.03 & 0.03 & 0.20 & 0.08 \\
\hline 174 & 0.17 & 0.15 & 0.15 & 0.08 \\
\hline 166 & 0.20 & 0.15 & 0.05 & 0.20 \\
\hline 160 & 0.08 & 0.08 & 0.05 & 0.10 \\
\hline 150 & 0.13 & 0.00 & 0.03 & 0.00 \\
\hline 144 & 0.30 & 0.05 & 0.10 & 0.03 \\
\hline 138 & 0.03 & 0.05 & 0.25 & 0.13 \\
\hline \multicolumn{5}{|l|}{$M F W 2$} \\
\hline 260 & 0.10 & 0.32 & 0.15 & 0.43 \\
\hline 238 & 0.00 & 0.13 & 0.25 & 0.32 \\
\hline 216 & 0.28 & 0.08 & 0.25 & 0.10 \\
\hline 200 & 0.00 & 0.00 & 0.05 & 0.03 \\
\hline 178 & 0.08 & 0.00 & 0.10 & 0.05 \\
\hline 170 & 0.43 & 0.17 & 0.13 & 0.05 \\
\hline 160 & 0.13 & 0.30 & 0.08 & 0.03 \\
\hline \multicolumn{5}{|l|}{ MFW11 } \\
\hline 210 & 0.00 & 0.00 & 0.08 & 0.13 \\
\hline 190 & 0.15 & 0.03 & 0.15 & 0.08 \\
\hline 174 & 0.08 & 0.30 & 0.20 & 0.05 \\
\hline 170 & 0.30 & 0.55 & 0.30 & 0.45 \\
\hline 164 & 0.25 & 0.05 & 0.22 & 0.30 \\
\hline 160 & 0.17 & 0.08 & 0.00 & 0.00 \\
\hline 124 & 0.05 & 0.00 & 0.05 & 0.00 \\
\hline \multicolumn{5}{|l|}{$M F W 15$} \\
\hline 264 & 0.03 & 0.13 & 0.08 & 0.10 \\
\hline 250 & 0.03 & 0.10 & 0.13 & 0.17 \\
\hline 240 & 0.05 & 0.20 & 0.17 & 0.10 \\
\hline 226 & 0.15 & 0.05 & 0.10 & 0.10 \\
\hline 198 & 0.08 & 0.10 & 0.13 & 0.17 \\
\hline 188 & 0.00 & 0.00 & 0.05 & 0.10 \\
\hline 184 & 0.17 & 0.00 & 0.08 & 0.10 \\
\hline 174 & 0.05 & 0.03 & 0.05 & 0.00 \\
\hline 166 & 0.25 & 0.13 & 0.00 & 0.08 \\
\hline 144 & 0.10 & 0.17 & 0.15 & 0.05 \\
\hline 136 & 0.10 & 0.10 & 0.08 & 0.03 \\
\hline \multicolumn{5}{|l|}{$M F W 20$} \\
\hline 230 & 0.03 & 0.00 & 0.08 & 0.10 \\
\hline 218 & 0.25 & 0.32 & 0.15 & 0.22 \\
\hline 200 & 0.30 & 0.25 & 0.22 & 0.32 \\
\hline 176 & 0.43 & 0.43 & 0.50 & 0.22 \\
\hline 168 & 0.00 & 0.00 & 0.05 & 0.13 \\
\hline $\mathrm{Na}$ & 5 & 9 & 3 & 4 \\
\hline
\end{tabular}

Na: Number of alleles lost across all loci 
The highest genetic distance value $(0.47)$ was between scaled carp and koi carp and the lowest $(0.23)$ was between red and koi carp (Table 5). The UPGMA dendrogram based on Nei's (1972) genetic distance resulted in two major clusters: the scaled carp was alone in one cluster while the remaining three strains grouped into another cluster. The second cluster was further segregated into two sub-clusters: mirror carp being alone in one cluster and red- and koi carp together in the other cluster (Figure 1).

Table 3 - Multilocus $F_{\mathrm{ST}}$ (upper diagonal) and $N_{\mathrm{m}}$ (below diagonal) values between pairs of four common carp strains across all loci.

\begin{tabular}{lcccc}
\hline & \multicolumn{4}{c}{ Common carp strain } \\
\cline { 2 - 5 } Populations & Scaled carp & Mirror carp & Red carp & Koi carp \\
\hline Scaled carp & & $0.055^{*}$ & $0.034^{*}$ & $0.071^{*}$ \\
Mirror carp & 5.48 & & $0.042^{*}$ & $0.046^{*}$ \\
Red carp & 7.36 & 6.84 & & $0.023^{\mathrm{NS}}$ \\
Koi carp & 4.56 & 6.50 & 9.67 & \\
\hline
\end{tabular}

$* \mathrm{p}<0.05$ and $\mathrm{NS}=$ not significant.

Table 4 - Homogeneity ( $\chi^{2}$ values) between samples of common carp strains.

\begin{tabular}{lcccc}
\hline & \multicolumn{4}{c}{ Common carp strain } \\
\cline { 2 - 5 } Strains & Loci & Mirror carp & \multicolumn{1}{c}{ Red carp } & \multicolumn{1}{c}{ Koi carp } \\
\hline Scaled & $M F W 1$ & $26.45(6)^{* * * *}$ & $28.27(6)^{* * * *}$ & $36.05(8)^{* * * *}$ \\
carp & MFW2 & $17.65(4)^{* *}$ & $22.75(5)^{* * *}$ & $46.54(5)^{* * * * *}$ \\
& MFW11 & $22.43(4)^{* * *}$ & $13.44(5)^{*}$ & $20.37(5)^{* *}$ \\
& $M F W 15$ & $21.74(8)^{* *}$ & $24.54(9)^{* *}$ & $17.81(9)^{*}$ \\
& $M F W 20$ & $0.78(2)$ & $4.60(3)$ & $11.45(4)^{*}$ \\
Mirror & $M F W 1$ & & $34.28(7)^{* * * *}$ & $13.28(6)^{*}$ \\
carp & $M F W 2$ & & $22.75(5)^{* * *}$ & $19.78(4)^{* * *}$ \\
& $M F W 11$ & & $13.08(4)^{*}$ & $23.33(4)^{* * *}$ \\
& $M F W 15$ & & $10.72(8)$ & $16.65(9)$ \\
Red & $M F W 20$ & & $9.87(3)^{*}$ & $16.10(4)^{* *}$ \\
carp & $M F W 1$ & & & $14.41(7)^{*}$ \\
& $M F W 2$ & & & $11.87(5)^{*}$ \\
& $M F W 11$ & & & $6.51(4)$ \\
& $M F W 15$ & & & $6.43(8)$ \\
& $M F W 20$ & & & $7.09(4)$ \\
\hline
\end{tabular}

${ }^{1}$ Values in parentheses indicate degrees of freedom and statistically significant values $\left(\chi^{2}\right.$ test $)$ are indicated as follows: $* \mathrm{p}<0.05 ; * \mathrm{p}<0.01$; $* * * \mathrm{p}<0.001 ;$ and $* * * * \mathrm{p}=0$.

Table 5 - Summary of Nei's (1972) genetic distance values between four common carp strains.

\begin{tabular}{lrcc}
\hline Populations & Scaled carp & Mirror carp & Red carp \\
\hline Scaled carp & & & \\
Mirror carp & 0.34 & & \\
Red carp & 0.30 & 0.29 & \\
Koi carp & 0.47 & 0.29 & 0.23 \\
\hline
\end{tabular}

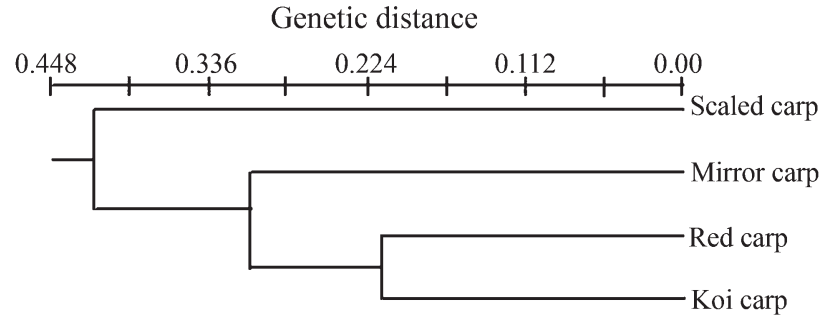

Figure 1 - Unweighted pair-group method with averages dendrogram based on Nei's (1972) genetic distance, summarizing the data on differentiation between C. carpio strains, according to microsatellite DNA analysis.

\section{Discussion}

In Bangladesh the common carp is an exotic species which contributes significantly to the aquaculture production of this country. However, since it is an exotic species its gene pool is restricted and subjected to various changes during the course of captive management. Though studies on genetic structure of this species are available elsewhere in the world (Kohlmann and Kersten, 1999; Tanck et al., 2000; David et al., 2001; Lehoczky et al., 2002; Bartfai et al., 2003; Kohlmann et al., 2003) our study is the first attempt to reveal the genetic structure of different strains of common carp introduced in Bangladesh.

The changes in gene and genotype frequencies of hatchery population are random and vary from stock to stock. Kohlmann and Kersten (1999) carried out an electrophoretic study of the allozymes of different strains of common carp and reported that the average number of allozyme alleles per locus was 1.4 to 1.9 , the mean $H_{0}$ was 0.112 to 0.256 and the percentage of polymorphic loci was 25 to 50 . The above study and the studies conducted by Sumantadinata and Taniguchi (1990) and Kohlmann et al. (2003) using common carp allozyme markers all showed lower genetic variability than that obtained in the present study. However, Lehoczky et al. (2002) used DNA microsatellite markers to study four strains of common carp and found an observed heterozygosity $\left(H_{0}\right)$ of 0.557 to 0.764 slightly higher than the 0.510 to 0.760 found by us. Bartfai et al. (2003) used microsatellite markers to study two Hungarian common carp stocks (Attala and Dinnyes) and reported that the mean $H_{\mathrm{o}}$ value was 0.69 and thus equal to the mirror carp value detected in our study, although the $H_{\mathrm{o}}$ value for scaled carp was higher than the value for scaled carp observed by us. Taken together, these studies suggest that microsatellite DNA markers may be more useful in analyzing subtle genetic differences among different stocks of common carp. In our study the number of lost microsatellite alleles for all loci varied from strain to strain, with the highest being 9 in mirror carp. Loss of allelic variation has also been reported for trout hatchery populations in Poland (Was and Wenne, 2002). Sekino et al. (2002) found that the number of microsatellite alleles was markedly reduced in 
hatchery strains of Japanese flounder compared with wild populations of the same species.

Loss of allelic variation in different strains of common carp may because common carp was introduced into Bangladesh in a few batches and bred repeatedly in hatchery units which had a small effective number of broods $\left(N_{\mathrm{e}}\right)$, which may have led to genetic drift and genetic erosion of most hatchery populations. The loss of heterozygosity may increase as bottlenecking and inbreeding increases, and Desvignes et al. (2001) have argued that the reduction of microsatellite allelic diversity in scaled carp and mirror carp could be related to population bottlenecking associated with breeding practices.

We found that red and koi carp showed more genetic variability than scaled and mirror carp, supporting the results reported by Liu et al. (2002) who studied the microsatellite markers of four artificially gynogenetic families of ornamental carp and found that each color strain of ornamental carp was produced through selective hybridization between strains. Zhou et al. (2004) also observed the highest level of genetic variability in terms of heterozygosity in Japanese decorative carp. In our study, although the average observed heterozygosity was highest in koi carp the average number of alleles observed in koi carp was more or less similar to that in red carp, indicating that both strains were very similar in terms of genetic variability. Moreover, although we found a significant departure from homogeneity between each pair of strains at the maximum number of loci (Table 4), our study supports the observation that koi and red carp are homogeneous at the maximum number of loci i.e. the genetic difference between koi and red carp is relatively low and it is probable that koi carps originated from red carp which are wild colored mutants of common carp (McDowall, 1989).

Our results showed that the $1-H_{\mathrm{o}} / H_{\mathrm{e}}$ values in koi carp were negative in most of the loci, which indicated relatively high level of heterozygosity in koi carp strain whereas significant positive values at different loci in different strains indicated a deficit of heterozygosity that could be the result of consanguinity due to preferential mating. Tessier et al. (1997) observed significant changes in allele frequencies and losses of low-frequency alleles but no reduction in heterozygosity in hatchery stocks in comparison with wild salmon populations. Since red carp and koi carp have only recently been introduced to the Jessore hatchery and only a few generations have been bred it is reasonable to expect them to show greater genetic variability than the scaled and mirror carp which had been bred at this hatchery for many generations.

For the five microsatellite loci tested in this study, all the strains were found to deviate from Hardy-Weinberg equilibrium at a number of loci, which might have been due to loss of heterozygosity in the hatchery populations because of the small effective population $\left(N_{\mathrm{e}}\right)$ and a bottleneck effect. This hypothesis is supported by the work of
Alam and Islam (2005), who found that a hatchery population of Catla catla deviated from Hardy-Weinberg equilibrium at a number of loci.

Pair wise genetic distance and $F_{\mathrm{ST}}$ values depicted the relationship in different strains of common carp. The close relationship with the least genetic distance and population genetic differentiation $\left(F_{\mathrm{ST}}\right)$ values observed between red carp and koi carp (Figure 1) might be due to the geographical proximity between the origins of the two strains and their breeding strategy. Both strains were introduced into Bangladesh from Japan and the koi carp is known to be derived through selective breeding from red carp (Kirpichnikov, 1981), as supported by the high gene flow $\left(N_{\mathrm{m}}\right)$ between the red carp and koi carp. In a previous analysis of mtDNA polymorphism among common carp populations from Europe and eastern and southern Asia, Gross et al. (2002) observed that the distribution of haplotypic groups strictly followed the geographic origin of the population and thus European populations which were genetically very similar to each other and less differentiated grouped into one cluster while koi- and Vietnamese carps were separated from each other with high genetic differentiation. However, we found that the scaled carp from China and Vietnam were only distantly related to the koi carp introduced from Japan, which had the highest genetic distance and $F_{\mathrm{ST}}$ values and the lowest $N_{\mathrm{m}}$ value. The significant departure from homogeneity between scaled carp and koi carp at all loci seen in our study supports these findings (Table 4). Similarly, Kohlmann and Kersten (1999) observed a discrete relationship between scaled carp and koi carp with relatively high level of genetic distance when analyzed with allozyme marker.

Our study has demonstrated that use of microsatellite markers is a powerful tool for monitoring the genetic condition of different strains of common carp in Bangladesh. Despite the loss of a number of alleles in different strains, significant differentiation was detected in different common carp pairs, except for the closely-related red and koi carp strains. Since common carp strains are exotic and widely cultured throughout Bangladesh, the genetic quality of the strains may possibly decline over the years due to the hatchery management practices used in Bangladesh. The only way to minimize genetic impact is to improve the genetic management for all strains by monitoring the genetic variability and accurately estimating the effective population size in hatcheries. Hatchery operators need to use molecular markers to monitor any genetic changes resulting from improper management practices in their hatcheries. Moreover the estimation of genetic variation and relatedness available in different common carp strains could be effective for planning future breeding programs and maintaining a diverse gene pool in different strains of common carp and brood stock management guidelines for hatcheries could be formulated to maintain genetic quality by monitoring genetic variability. However, genetic analysis with 
more markers and samples covering different hatcheries throughout Bangladesh still need to be performed to formulate a good management policy for the common carp strains used in Bangladesh now and in the future.

\section{Acknowledgments}

This study was conducted under grant number MOSICT/ sec-9/SAP-28/2003-2004/528 of the Ministry of Science and Information \& Communication Technology (MoSICT), Government of the Peoples' Republic of Bangladesh. The Authors are indebted to two unknown referees who helped improve the manuscript.

\section{References}

Alam MS and Islam MS (2005) Population genetic structure of Catla catla (Hamilton) revealed by microsatellite DNA markers. Aquaculture 246:151-160.

Alam MS, Popplewell A and Maclean N (1996) Germline transmission and expression of a lacZ containing transgene in tilapia (Oreochromis niloticus). Transgenic Res 5:87-95.

Ali ML (1998) Fisheries resources development and management technique. Fish Week' 98 Compendium. Department of Fisheries, Ministry of Fisheries and Livestock, Dhaka, pp $1-10$.

Bartfai R, Egedi S, Yue GH, Kovacs B, Urbanyi B, Tamas G, Horvath L and Orban L (2003) Genetic analysis of two common carp broodstocks by RAPD and microsatellite markers. Aquaculture 219:157-167.

Basavaraju Y, Penman DJ and Mair GC (2002) Genetic status and strategies for improvement of common carp (Cyprinus carpio) in Karnataka, India - Evaluation of stocks for the development of a breeding programme. In: Penman DJ, Hussain MG, McAndrew BJ and Mazid MA (eds) Proceedings of a Workshop on Genetic Management and Improvement Strategies for Exotic Carps in Bangladesh. Bangladesh Fisheries Research Institute, Mymensingh, pp 29-36.

Crooijmans RPMA, Bierbooms VAF, Komen J, van der Poel JJ and Groenen MAM (1997) Microsatellite markers in common carp (Cyprinus carpio L.). Anim Genet 28:129-134.

David L, Rajasekaran PJ, Fang J, Hillel J and Lavi U (2001) Polymorphism in ornamental and common carp strains (Cyprinus carpio L.) as revealed by AFLP analysis and new set of microsatellite markers. Mol Genet Genomics 266:353-362.

Desvignes JF, Laroche J, Durand JD and Bouvet Y (2001) Genetic variability in reared stocks of common carp (Cyprinus carpio L.) based on allozymes and microsatellites. Aquaculture 194:291-301.

FAO (2005) World Aquaculture Production of Fish, Crustaceans, Molluscs, etc., by Principal Species in 2003. Yearbook of Fishery Statistics. http://www.fao.org/fi/statist/statist.asp.

Gross R, Kohlmann K and Kersten P (2002) PCR-RFLP analysis of the mitochondrial $N D-3 / 4$ and $N D-5 / 6$ gene polymorphisms in the European and East Asian subspecies of common carp (Cypriunus carpio L.). Aquaculture 204:507-516.

Goudet J (2001) FSTAT, a program to estimate and test gene diversities and fixation indices (version 2.9.3). Available from http://www.unil.ch/izea/softwares/fstat.html. Updated from Goudet (1995).

Hamada H, Petrino MG and Kakunaga T (1982) A novel repeated element with Z-DNA-forming potential is widely found in evolutionary diverse eukaryotic genomes. Proc Natl Acad Sci USA 79:6465-6469.

Hulata G (1995) A review of genetic improvement of the common carp (Cyprinus carpio L.) and other cyprinids by crossbreeding, hybridization and selection. Aquaculture 129:143-155.

Hussain MG (1997) Current status of carp genetic research and breeding practices in Bangladesh. In: Gupta MV, Dey MM, Dunham R and Bimbao G (eds) Proceedings of the Collaborative Research and Training on Genetic Improvement of Carp Species in Asia. Central Institute of Freshwater Aquaculture, Bhubaneshwar. ICLARM Work Documents 1 (unpublished), $12 \mathrm{p}$.

Kirpichnikov VS (1981) Genetic Bases of Fish election. Springer-Verlag, Berlin, 410 pp.

Kohlmann K and Kersten P (1999) Genetic variability of German and foreign common carp (Cyprinus carpio L.) populations. Aquaculture 173:435-445.

Kohlmann K, Gross R, Murakaeva A and Kersten P (2003) Genetic variability and structure of common carp (Cyprinus carpio) populations throughout the distribution range inferred from allozyme, microsatellite and mitochondrial DNA markers. Aquat Living Resour 16:421-431.

Lehoczky I, Magyary I and Hancz C (2002) Study of the genetic variability of six domestic common carp strains using microsatellite DNA markers. Allattenyesztes es Takarmanyozas 51:8-19.

Lewis PO and Zaykin D (2001) Genetic Data Analysis. Computer program for the analysis of allelic data. Version 1.0 (d 16c). Free program distributed by the authors over the internet from http://lewis.eeb.uconn.edu/lewishome/software.html.

Liu JX, Zhou L, Zhao ZS and Gui JF (2002) Studies on microsatellite markers of four artificially gynogenetic families in ornamental carp. Zool Res 23:97-105.

McDowall A (1989) The Interpret Encyclopaedia of Koi. Salamander Books, London, 208 pp.

Nash JHE (1991) DNA frag, Version 3.03. Institute for Biological Sciences, National Research Council of Canada, Ottawa, Ontario, Canada.

Nei M (1972) Genetic distance between populations. Am Nat 106:283-292.

Nelson RJ (1994) Fishes of the World. 3rd edition. Wiley, New York, $600 \mathrm{pp}$.

Page RDM (1996) TREEVIEW: An application to display phylogenetic trees on personal computers. Comput Appl Biosci 12:357-358.

Purdom CE (1993) Genetics and Fish Breeding. Fish and Fisheries Series 8. Chapman and Hall, London, 277 pp.

Rahman AKM (1985) Study on the exotic fishes in Bangladesh. Paper presented at a seminar on the Culture Need of Exotic Species in Bangladesh, organized by the Zoological Society of Bangladesh, Dhaka, $13 \mathrm{p}$.

Schaffer HE and Sederoff RR (1981) Improved estimation of DNA fragment lengths from agarose gels. Anal Biochem 115:113-122.

Sekino M, Hara M and Taniguchi N (2002) Genetic diversity within and between hatchery strains of Japanese flounder 
Paralichthys olivaceus assessed by means of microsatellite and mitochondrial DNA sequencing analysis. Aquaculture 213:101-122.

Siegismund HR (1995) G-STAT, Version 3.1. Genetical statistical programs for the analysis of population data. Botanical Institute, University of Copenhagen, Denmark.

Sumantadinata K and Taniguchi N (1990) Comparison of electrophorectic allele frequencies and genetic variability of common carp stocks from Indonesia and Japan. Aquaculture 88:263-271.

Tanck MWT, Baars HCA, Kohlmann K, Komen J and van der Poel JJ (2000) Genetic characterization of wild Dutch common carp (Cyprinus carpio L.). Aquac Res 31:779-783.
Tessier N, Bernatchez L and Wright JM (1997) Population structure and impact of supportive breeding inferred from mitochondrial and microsatellite DNA analyses in land-locked Atlantic salmon Salmo salar L. Mol Ecol 6:735-750.

Was A and Wenne R (2002) Genetic differentiation in hatchery and wild sea trout (Salmo trutta) in the Southern Baltic at microsatellite loci. Aquaculture 204:493-506.

Yeh FC, Yang RC and Boyle T (1999) POPGENE Version 1.31: Microsoft Window-based free software for Population Genetic Analysis. http://www.ualberta.ca/ fyeh.

Zhou J, Wu Q, Wang Z and Ye Y (2004) Genetic variation analysis within and among six varieties of common carp (Cyprinus carpio L.) in China using microsatellite markers. Russ J Genet 40 (10):1144-1148.

Associate Editor: Fausto Foresti 